International Journal of Thin Films Science and Technology

http://dx.doi.org/10/12785/ijtfst/020209

\title{
Influence of Sulphur on structural and electrical properties of $\mathrm{PbS}_{\mathrm{X}} \mathrm{Se}_{1-\mathrm{x}}$ films
}

\author{
Eman M. Nasir, N.K.Abas , S.J.Alatya \\ Department of Physics College of Science, Baghdad University, Baghdad. Iraq
}

Received: 23 July. 2012, Revised: 19 Jan. 2013; Accepted: 20 Mar. 2013

Published online: 1 May 2013

\begin{abstract}
PbS}_{\mathrm{x}} \mathrm{Se}_{1-\mathrm{x}}$ alloys with different $\mathrm{S}$ content $(0,0.1,0.15,0.3,0.4,1)$ have been successfully prepared by evacuated quartz tube under vacuum pressure $\left(10^{-2}\right.$ Toor). $\mathrm{PbS}_{\mathrm{x}} \mathrm{Se}_{1-\mathrm{x}}$ thin films have been prepared by thermal evaporation technique on glass substrate at room temperature (RT) under vacuum pressure $10^{-5} \mathrm{mbar}$ at deposition rate $5 \mathrm{~nm} / \mathrm{sec}$. The effect of $\mathrm{S}$ content on some of the electrical properties has been studied.The structure of $\left(\mathrm{PbS}_{\mathrm{x}} \mathrm{Se}_{1-\mathrm{x}}\right)$ alloys and films have been studied by X-ray diffraction technique. X-ray diffraction study shows that the Structure is polycrystalline with cubic Structure with preferential orientation in the (200) direction for films.

From D.C measurements all films have shown two activation energies, the first at low temperature for activation energy $\mathrm{E}_{\mathrm{a} 2}$ and the second at high temperature for activation energy $E_{a 1}$, where these value decreases with increasing $S$ content. And it is found that D.C conductivity decreased with increasing $\mathrm{S}$ content, while activation energy increases with increasing $\mathrm{S}$ content.. From the Hall measurement, the films of $(X=0,0.1,0.15,0.3,0.4)$ are $n$-type and the films of $(X=1)$ are $p$-type. Also the results showed that the carriers concentration decreases with increasing $S$ content, but the Hall mobility $\mu_{H}$ increased, and the value of $R_{H}$ (decreased with increasing $\mathrm{S}$ content.
\end{abstract}

Keywords: Control PbS, PbSe, PbSxSe1-x, x alloys, electrical properties, ternary compounds

\section{Introduction}

Group IV-VI semiconductors and their heterostructures are well-known to form ternary and quaternary alloys with a direct fundamental band gap over most of alloy composition range with high absorption coefficients, which can be used as materials for fabricating thin film heterojunction photovoltaic (PV) devices. The two compounds $\mathrm{PbS}$ and $\mathrm{PbSe}$, which are direct gap semiconductors at the $\mathrm{L}$ point of the Brillouin zone, form a continuous series of alloys denoted by PbS1-xSex, The two compounds $\mathrm{PbS}$ and $\mathrm{PbSe}$, which are direct gap semiconductors at the $\mathrm{L}$ point of the Brillouin zone, form a continuous series of alloys denoted by $\mathrm{PbS} 1-\mathrm{xSex}$ [1]. There are many experimental studies for the mixture of $\mathrm{PbS}$ and PbSe compounds. For example Javeed Akhtar et al[2] have prepared Truly alloyed $\mathrm{PbS}_{\mathrm{x}} \mathrm{Se}_{1-\mathrm{x}}(\mathrm{x}=0-1)$ nanocrystals $(\sim 5 \mathrm{~nm}$ in size $)$, and their resulting optical properties are red-shifted systematically as the sulfur content of the materials increases. And Wanli Ma et al[3] have reported on Photovoltaic Devices Employing Ternary $\mathrm{PbS}_{x} \mathrm{Se}_{1-x}$ Nanocrystals, and they found that Photovoltaic devices made using ternary nanoparticles are more efficient than either pure $\mathrm{PbS}$ or pure $\mathrm{PbSe}$ based nanocrystal devices. The continuous variation of electrical and optical properties of ternary alloy semiconductors with relative concentration of constituents is of utmost utility in development of solid state technology. In view of their technological importance in remote sensing [4], thermography chemical sensing [5] and long wavelength imaging, the narrow gap semiconductors have been a subject of extensive interest, because the Lead salts and their alloys have a number of interesting physical properties as well as numerous potential 
applications [6]. Kumar et al[7] have studied the Solid solutions of $\mathrm{PbS}_{1-\mathrm{x}} \mathrm{Se}_{\mathrm{x}}$ system by taking the ingredients i.e. lead, sulphur and selenium in their elemental form, and prepared thin films of the alloy by flash evaporation of the fused material on the glass substrate at room temperature. And they studied the electrical properties viz. resistivity, Hall co-efficient, carrier concentration and mobility of the carriers. Also they studied the optical and structural properties. The absorption edge shifts towards longer wavelength side. Consequently the energy band gap becomes narrower. The electrical resistivity is also found to decrease which proves their utility at longer wavelengths. XRD patterns reveal the crystalline nature of the film which is also confirmed by SEM photographs at room temperature. The electrical properties depend upon the nature of semiconductor, if they are pure or doped and crystalline or amorphous ${ }^{[8]}$. The aim of this work is to investigate the effect of variation of $\mathrm{S}$ content on the structural and electrical properties of $\mathrm{PbS}_{\mathrm{x}} \mathrm{Se}_{1-\mathrm{x}}$.

\section{Experimental}

The $\mathrm{PbS}_{\mathrm{x}} \mathrm{Se}_{1-\mathrm{x}}$ alloys were prepared from pure lead and sulfur and selenium powders whose purity is about $(99.9999 \%)$ with different $\mathrm{x}$ content where $\mathrm{x}(0,0.1,0.15,0.3,0.4,1)$ the weighted lead ,sulfur and selenium were loaded into a clean and baked quartz tube, these alloys are powdered to a fine grain powder. The powder of the compounds was as a source of the evaporation to prepare the films. The $\mathrm{PbS}_{\mathrm{x}} \mathrm{Se}_{1-\mathrm{x}}$ films have been prepared by thermal evaporation technique using Edward E306A under lower pressure of about $10^{-6}$ mbar with $(0.3 \mu \mathrm{m}$ thickness. By the thermal evaporation techniques, the weighting of the required amount of material placed into molybdenum boat. When the vacuum system reaches the pressure $\left(10^{-5}\right) \mathrm{mbar}$ at deposition $(5 \mathrm{~nm} / \mathrm{sec})$, the deposition processes is carried out by instantaneous evaporation of the material with minimum possible time of contact with the evaporator by controlling on it by vibrators. The structure of alloy and films were studied by XRD with $\mathrm{Cu}-\mathrm{K} \alpha$ wavelength ( $\lambda$ ) (1.5405)A. The electrical measurements are included D.C conductivity, Hall Effect measurement. The electrical resistance has been measured as a function of the temperature (T). The measurements have been done with used sensitive electrometer type of (Keithley Digital Electrometer (616) and vacuum electric oven. The resistivity and conductivity as a function of thickness and the activation energy can be calculated from these measurements. By plots the $(\mathrm{Ln} \sigma)$ vs. reciprocal of the absolute temperature $\left(10^{3} / \mathrm{T}\right)$, we can measure the activation energy by taking the slope of straight lines which represent $(-\Delta \mathrm{E} / \mathrm{K})$ and multiplying it by Boltzmann constant. The type, concentration and mobility of the carrier for $\mathrm{PbS}_{\mathrm{x}} \mathrm{Se}_{1-\mathrm{x}}$ films can be calculated.

\section{X-ray diffraction}

Fig.3.1. show the $\mathrm{X}$-ray diffraction for $\mathrm{PbS}_{\mathrm{x}} \mathrm{Se}_{1-\mathrm{x}}$ films with $\mathrm{x}$ content $(0,0.1,0.15,0.3,0.4,1)$, it appears that these films are polycrystalline of FCC cubic structure according to ASTM cards. And this agreement with R.Kumar et.al [7]. From the X-ray patterns of the prepared films, Fig.3.2. and the Table.3.1. shows that the intensity increases with the increasing of sulfide $S$ content, this increase be more significant at higher S concentration, this indicates that (200) direction are the preferred plane for the crystal growth. The $d$-values of the lines obtained in the XRD patterns were calculated and compared with the corresponding values for $\mathrm{PbS}_{\mathrm{x}} \mathrm{Se}_{1-\mathrm{x}}$ taken from the JCPDS card. Well-defined (111), (200), (220), (311), 
(222) peaks were observed in the XRD pattern as shown in Fig.3.1.This figure shows crystallize with a strong peak at (200) direction and the intensity of other planes increases with increasing S content. Such data have also obtained by other researcher $[9,10]$ and there is a little shifting toward higher diffraction angle with increasing $\mathrm{x}$ content. The Table.3.1. shows the obtained values of interplaner spacing of $\mathrm{PbS}$, $\mathrm{PbSe}$ alloys and $\mathrm{PbS}_{\mathrm{x}} \mathrm{Se}_{1-\mathrm{x}}$ films for different values of $\mathrm{x}$, Similar result has been also shown by $[9,11,12]$. The grain size of the films was determined by using Scherrer formula:

$$
D=0.9 \lambda / \cos \theta
$$

Where D is the particle size $\lambda$ the wavelength for the XRD Source, is the Full Wave at half Maximum (FWHM), $\theta$ is the angel for X-Ray radiation, Fig.3.2 shows variation of grain size from $29.53-82.10 \mathrm{~nm}$ with $\mathrm{S}$ content, which shows that the crystallinity of $\mathrm{PbS}_{\mathrm{x}} \mathrm{Se}_{1-\mathrm{x}}$ films increases with $\mathrm{x}$ content.

Table 3.1: XRD parameters for $\mathrm{PbS}_{\mathrm{x}} \mathrm{Se}_{1-\mathrm{x}}$ films for (200).

\begin{tabular}{|c|c|c|c|c|c|}
\hline Films & $(\mathrm{deg})^{2 \theta}$ & $\begin{array}{l}D_{\text {spacin }} \\
\mathrm{g} \\
(\AA ̊)\end{array}$ & $a(\AA)$ & $\mathrm{D}(\mathrm{nm})$ & $\begin{array}{l}\text { FWHM } \\
\text { ( } \beta \text { )deg }\end{array}$ \\
\hline $\mathrm{PbSe}$ & 29.246 & 3.051 & 6.102 & 29.53 & 0.290 \\
\hline $\mathrm{PbS}_{0.1} \mathrm{Se}_{0.9}$ & 29.231 & 3.052 & 6.105 & 17.78 & 0.482 \\
\hline $\mathrm{PbS}_{0.15} \mathrm{Se}_{0.85}$ & 29.352 & 3.040 & 6.080 & 29.81 & 0.287 \\
\hline $\mathrm{PbS}_{0.3} \mathrm{Se}_{0.7}$ & 29.375 & 3.038 & 6.076 & 29.05 & 0.295 \\
\hline $\mathrm{PbS}_{0.4} \mathrm{Se}_{0.6}$ & 29.511 & 3.024 & 6.048 & 60.03 & 0.614 \\
\hline $\mathrm{PbS}$ & 30.175 & 2.959 & 5.918 & 82.10 & 0.104 \\
\hline
\end{tabular}

\section{Resistivity and conductivity measurements}

Figure.4.1. and Figure.4.2. shows the variation of conductivity and resistivity of the samples with increasing sulphur content. The conductivity decreases continuously with increasing sulphur content except for a sulfur concentration $(x=0.3)$. The conductivity of the alloy films lies in between the conductivity of $\mathrm{PbS}$ and that of $\mathrm{PbSe}$. The conductivity of $\mathrm{PbS}$ is the lowest one. The successive decrease in resistivity on partial substitution of selenium by sulphur is accounted for the increased the grain size . The increase in grain size can be seen By the XRD photograph. The dependence of the resistivity of a film on the mean grain size at room temperature is also reported by R. KUMAR [7,13]. When selenium is completely replaced by sulphur then the lowest resistivity material PbSe is formed as the carrier density of $\mathrm{PbSe}$ is higher than that of $\mathrm{PbS}$. The only rise in resistivity is at the point, where $\mathrm{S}$ is in excess. It is due to the inhomogeneity introduced in the solid solution. The rise in resistivity at higher $\mathrm{S}$ contents may also be attributed to the surface scattering effects due to imperfect matching of the various areas of the growing films[7]. 

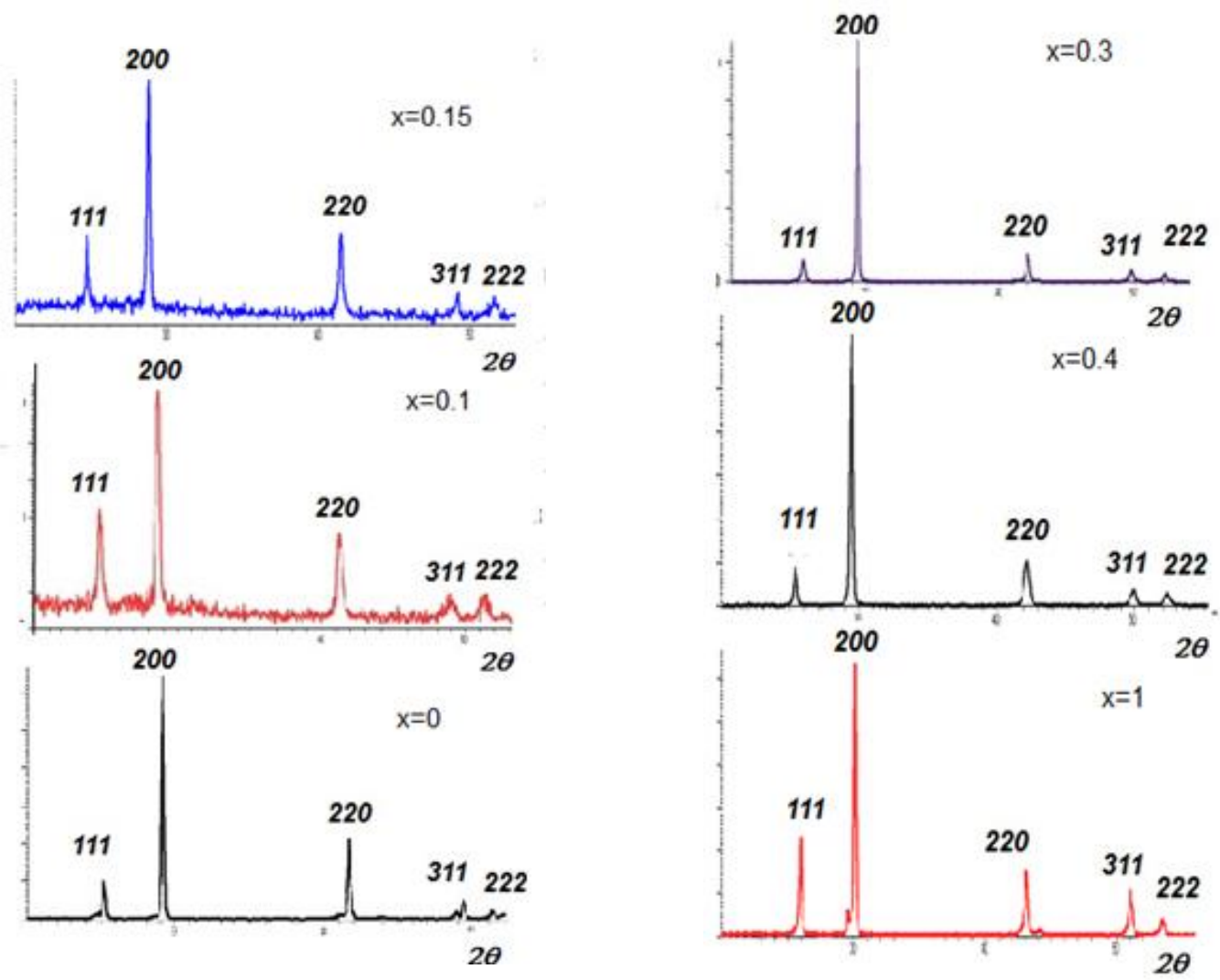

Figure 3.1: $\mathrm{X}$-ray diffraction of $\mathrm{PbS}_{\mathrm{x}} \mathrm{Se}_{-1 \mathrm{x}}$ films at different $\mathrm{x}$ content.

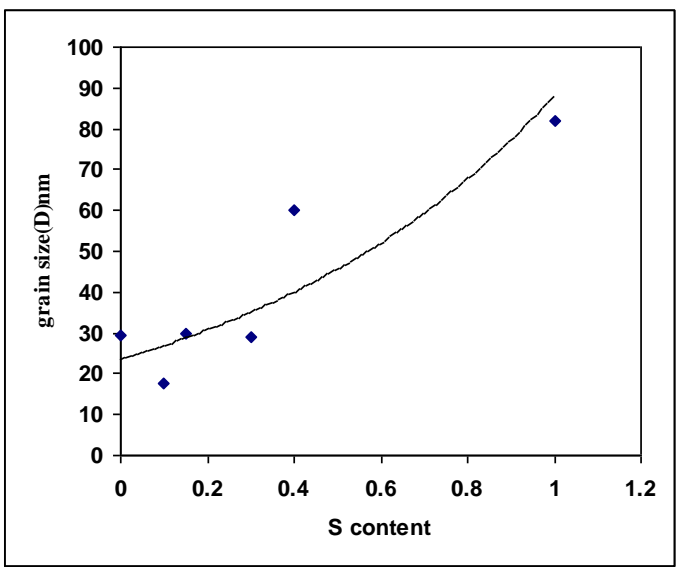

Figure 3.2: variation of grain size with $S$ content. 


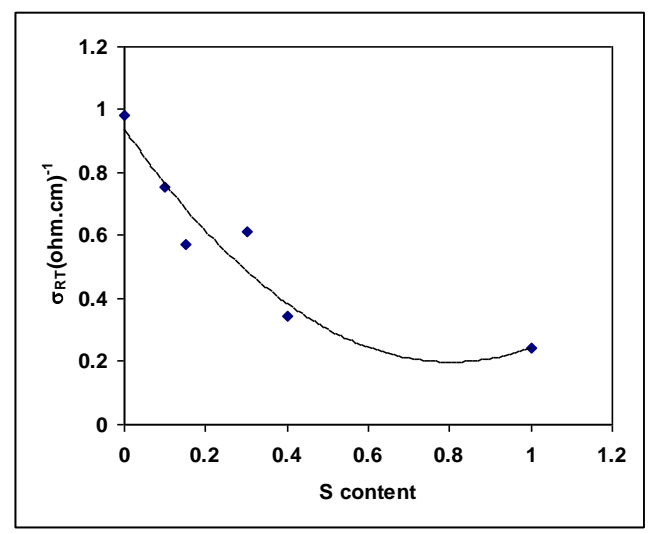

Figure 4.1: the variation of conductivity with $\mathrm{S}$ content.

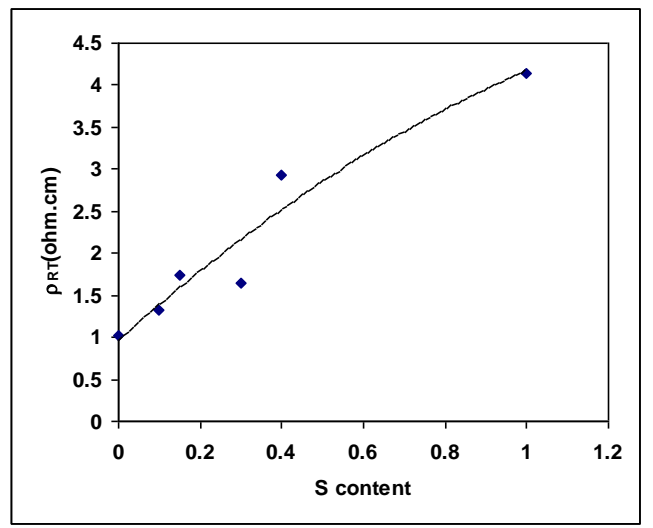

Figure 4.2: the variation of resistivity with $\mathrm{S}$ content

\section{Activation Energy}

The plots of $\ln \sigma$ versus 103/T for $\mathrm{PbS}_{\mathrm{x}} \mathrm{Se}_{1-\mathrm{x}}$ films in the range $(298-493) \mathrm{K}$ at different $\mathrm{S}$ content $(0,0.1,0.15,0.3,0.4,1)$ are shown in Figure.5.1a-f. In general, it can be observed from this figure that the D.C conductivity decreases with increasing S content. This decrease means a negative coefficient of resistance. It is obvious from this figure that there are two transport mechanisms, giving rise to two activation energies $E_{a 1}$ and $E_{a 2}$. The conduction mechanism of the activation energy $\left(E_{a 1}\right)$ at the higher temperatures is due to carrier's excitation into the extended states beyond the mobility edge, and the activation energy $\left(\mathrm{E}_{\mathrm{a} 2}\right)$ at the lower range of temperatures, the conduction mechanism is due to carrier's excitation into localized state at the edge of the band.Figure.5.2. and Table.5.1. show the effect of $x$ content on both activation energies $\mathrm{E}_{\mathrm{a} 1}$ and $\mathrm{E}_{\mathrm{a} 2}$ for $\mathrm{PbS}_{\mathrm{x}} \mathrm{Se}_{1-\mathrm{x}}$ films. It is obvious that the activation energies increase with increasing of the $S$ content for $X=.(0,0.1,0.15,0.3,0.4,1)$, The increasing in the activation energy with increasing of $S$ content may be due to the increase of the energy gap with the increasing of composition and to change in the localized states, structure and composition of films as well as to the rearrangement of atoms, which yields fewer defects, there is reduction in the density of state 
which occurs at Fermi level which caused to transfer from conductivity near Fermi level to the thermal activation conductivity at band gap. These results are in agreement with R.Kumar et al.[ 7,14].
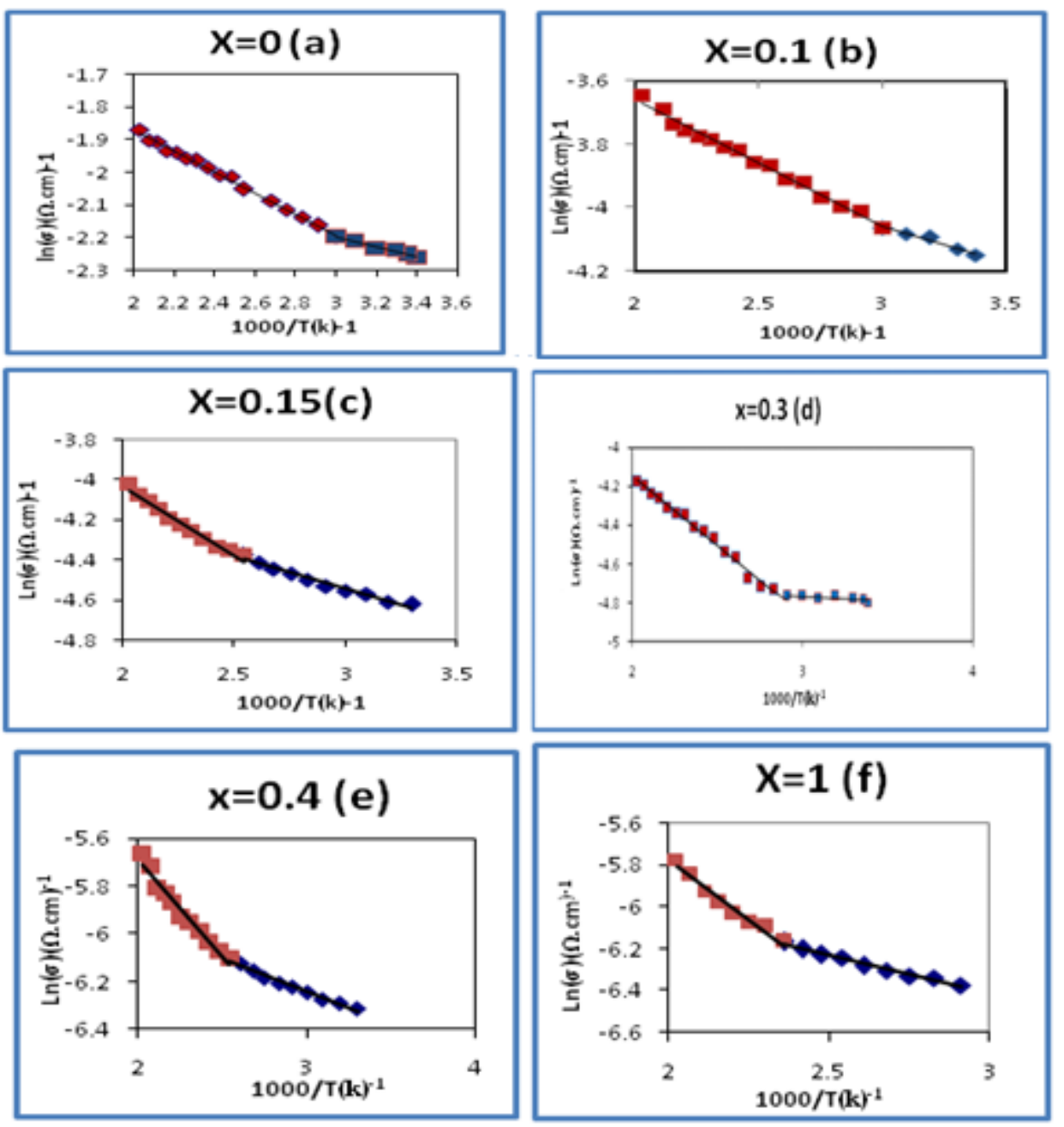

Figure 5.1: The plots of $\ln \sigma$ versus $10 /^{3} \mathrm{~T}$ for $\mathrm{PbS}_{\mathrm{x}} \mathrm{Se}_{-1 \mathrm{x}}$ at different $\mathrm{x}$ content.
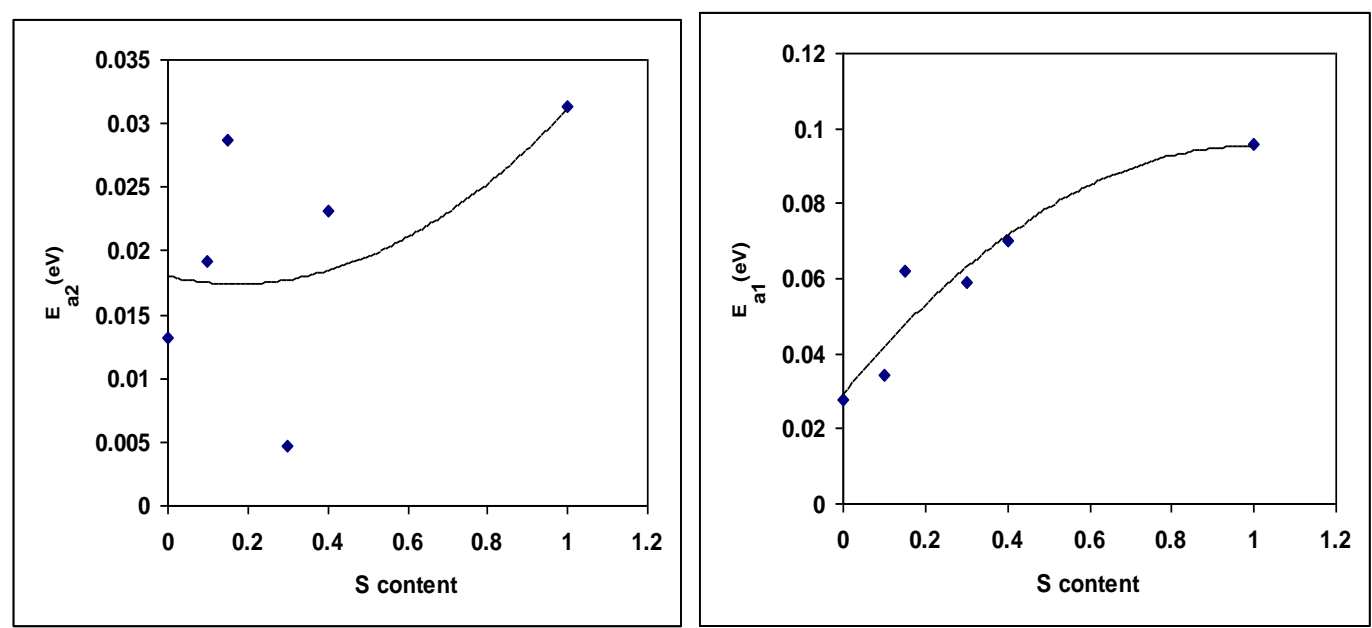

Figure 5.2: The variation of activation energy with $S$ content 
Table 5.1: The Electrical parameters of PbSxSeI-x films.

\begin{tabular}{|l|l|l|l|}
\hline Alloy & $\begin{array}{l}\sigma_{\mathrm{RT}}(\Omega . \mathrm{cm})^{1-} \\
10^{-2}\end{array}$ & $\mathrm{E}_{\mathrm{a} 1} \mathrm{eV}$ & $\mathrm{E}_{\mathrm{a} 2} \mathrm{eV}$ \\
\hline $\mathrm{PbSe}$ & 0.982 & 0.0275 & 0.0132 \\
\hline $\mathrm{PbS}_{0.1} \mathrm{Se}_{0.9}$ & 0.753 & 0.0344 & 0.0192 \\
\hline $\mathrm{PbS}_{0.15} \mathrm{Se}_{0.85}$ & 0.572 & 0.0618 & 0.0287 \\
\hline $\mathrm{PbS}_{0.3} \mathrm{Se}_{0.7}$ & 0.611 & 0.0591 & 0.0047 \\
\hline $\mathrm{PbS}_{0.4} \mathrm{Se}_{0.6}$ & 0.342 & 0.0703 & 0.0232 \\
\hline $\mathrm{PbS}$ & 0.241 & 0.0957 & 0.0313 \\
\hline
\end{tabular}

\section{Carrier concentration, carrier type and Hall mobility}

Carrier concentration $\left(n_{H}\right)$, carrier type and Hall mobility $\left(\mu_{H}\right)$, have been determined from Hall measurements for $\mathrm{PbS}_{\mathrm{x}} \mathrm{Se}_{1-\mathrm{x}}$ thin films at different $\mathrm{S}$ contents as shown in Table.6.1. We can notice from this table that the films have a negative Hall coefficient $\left(\mathrm{R}_{\mathrm{H}}\right)$ (n-type charge carriers), and p-type for $(X=1)$ films, Similar results were obtained by[15-18].

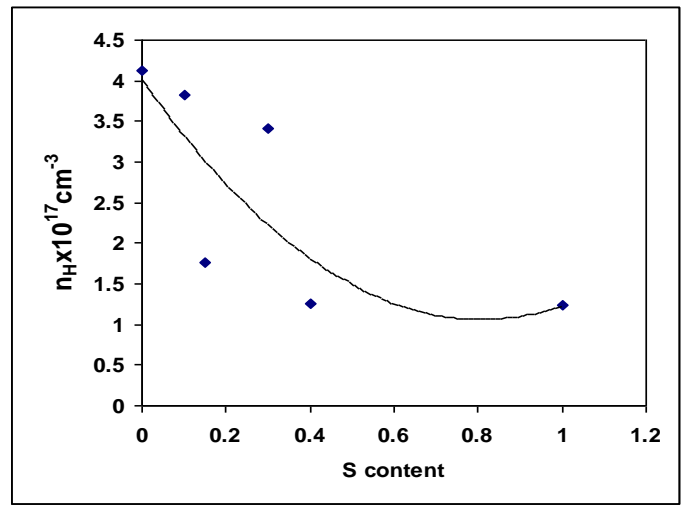

Figure 6.1: The variation of carrier concentration with $S$ content.

The carrier concentration of these samples is plotted in Figure.6.1. with increasing S content. It attains reasonably high value when $\mathrm{S}$ is added substitutionally with selenium. At higher $\mathrm{S}$ concentrations the carrier density decreases and becomes smallest when all the selenium is replaced by sulphur. The primary increase in carrier concentration of these samples, on partial replacement of selenium, is because of the higher carrier concentration of $\mathrm{PbSe}$ than that of $\mathrm{PbS}$, while the succeeding decrease is proposed to be due to the grain boundary effects which are supposed to dominate in the intermediate range of substitution. Since there is a large concentration of defects at grain boundaries such as trapping states stacking faults 
and surface states resulting from the incomplete atomic bonding. These states trap the free charge carriers thus reducing the carrier density. At further high Se contents when PbSe is formed these traps vanish since $\mathrm{PbSe}$ has fewer defects than ternary alloy $\mathrm{PbS}_{1-\mathrm{x}} \mathrm{Se}_{\mathrm{x}}$ but still there are sufficient free carriers to enhance the carrier concentration due to higher carrier density of $\mathrm{PbSe}$.

While the Hall mobility $\left.{ }_{\mathrm{H}}\right)$ increase with increasing $(\mathrm{S})$ content except $(\mathrm{X}=0.3)$ as shown in Figure.6.2. This result is in agreement with the result of J.D. Jensen \& R.B. Schoolar [10], R. Neumann et al[11], A. Rogalski \& K. Jozwikow ski [18], This may be due to the decrease in defects inside the energy gap and to the transformation to crystalline structure and either decreasing the trapping centers for the films and reduction of the scattering of the carriers from the surface as well as the elimination of the defects in the films( as it is seen from the X-ray study[7] and the increasing in crystallite size that decreasing the number of grain boundaries. Also on increasing the $\mathrm{S}$ concentration further, the mobility increases due to enhanced mean free path resulting from the decrease in carrier density.

Table 6.1: Hall parameters for $\mathrm{PbS}_{\mathrm{x}} \mathrm{Se}_{1-\mathrm{x}}$ films at different $\mathrm{x}$.

\begin{tabular}{|lll|l|}
\hline$x$ & $\left(\mathrm{n}_{\mathrm{H}}\right) \times 10^{17}$ & $\begin{array}{l}\mu_{\mathrm{H}}\left(\mathrm{cm}^{2} / \mathrm{V}\right. \\
. \mathrm{s})\end{array}$ & Type \\
\hline $\mathrm{cm}{ }^{-3}$ & 4.124 & 27.24 & $\mathrm{~N}$ \\
$\mathrm{PbS}_{0.1} \mathrm{Se}_{0.9}$ & 3.825 & 244.1 & $\mathrm{~N}$ \\
$\mathrm{PbS}_{0.15} \mathrm{Se}_{0.85}$ & 1.763 & 447.3 & $\mathrm{~N}$ \\
$\mathrm{PbS}_{0.3} \mathrm{Se}_{0.7}$ & 3.405 & 396.1 & $\mathrm{~N}$ \\
$\mathrm{PbS}_{0.4} \mathrm{Se}_{0.6}$ & 1.263 & 658.4 & $\mathrm{~N}$ \\
$\mathrm{PbS}$ & 1.23 & 764.0 & $\mathrm{p}$
\end{tabular}

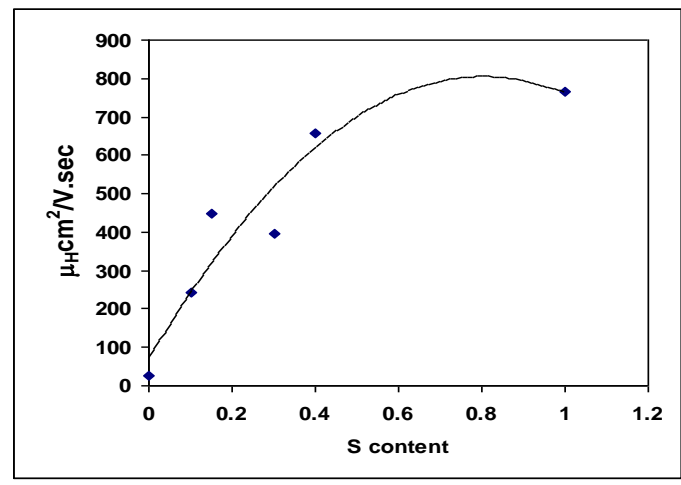

Figure 6.2: The variation of mobility with $S$ content. 


\section{Conclusions}

The electrical properties of these films are great importance in infrared detectors, light-emitting devices and as infrared lasers in fiber optics, as thermoelectric materials and in window coatings. The $\mathrm{Pb}_{\mathrm{x}} \mathrm{S}_{1-\mathrm{x}}$ alloys for $(\mathrm{x}=0,0.1,0.15,0.3,0.4,1)$ have successfully prepared, as bulks and films. X-ray diffraction study shows that the Structure is polycrystalline with cubic Structure with preferential orientation in the (200) direction. And the mechanism of conductivity occurs in two ranges of temperature. The d.c conductivity decreases with increasing the $S$ content for all $x=0.3$. The electrical activation energy increases at a range of temperatures (RT-498K) with increasing $S$ content. Hall measurement shows that the films of $(\mathrm{x}=0,0.1,0.3$, and 0.4$)$ are $n$-type and the films of $(\mathrm{x}=1)$ are $\mathrm{p}$-type .The carriers concentration decreases with increasing $S$ content except of $(X=0.3)$. Hall mobility increases with increasing $\mathrm{S}$ content while it decreases for $(\mathrm{x}=0.3)$.

\section{Acknowledgements}

This work was achieved at the thin film laboratory, Physics Departments, College of science, Baghdad University. Thanks to head of the group of thin film laboratory and all staff in it for there assistant.

\section{References}

[1] M. Labidi, H. Meradji, S. Ghemid and S. Labidi, Structural, Electronic, Optical and Thermodynamics Prpoperties of PbS, PbSe and their Ternary alloy PbS1-xSex,, Modern Physics Letters B, 25 (2011) 473-486.

[2] Javeed Akhtar, Mohammad Afzaal, Mateusz Banski, et al, Controlled Synthesis of Tuned Bandgap Nanodimensional Alloys of PbSxSe1-x, J. Am. Chem. Soc,. 133(2011) 5602-5609.

[3] Wanly Ma, Joseph M. Luther, Haimei Zheng, Yue Wu, A. Paul Alivisatos, Photovoltaic Devices Employing Ternary PbSxSe1-x Nanocrystals, Nano Letters, 9,(2009)1699-1703.

[4] N. Zemel, C. G. Scott, C. Z. Roed(Eds), Surface Physics Of Phosphorous and Semi Conductors. Academic Press. London (1975)523.

[5] H. Holloway, Thin Film IV-VI Semi Conductor Photodiodes, Physics of Thin Films Academic Press, New York, 11(1980)105.

[6] D. L.Carter, R. T. Bates (Eds). The physics of Semimetals and Narrow Gap Semi Conductors, Pergamon, New York, (1970).

[7] R. Kumar ,G. Jain ,R. Saini \& P. Agrawal , Compositional effects on properties of PbS1-x Sex thin films, Chalcogenide Letters, 7, (2011)233-240.

[8] Pankove, "Optical Processes in Semiconductors", Prentice - Hall, Inc., Englewoodcliffs, New Jersy ,285 (1971) 111.

[9] K. S. Sree Harsha ,"Principles Of Physical Vapor Deposition Of Thin Films" 1st edition ,2006.

[10] J.D. Jensen \& R.B. Schoolar, Surface charge transport in PbSxSe1-x and Pb1-ySnySe epitaxial films ,J.Vac. Sci. Technol, 13, (1976)920925.

[11] R. Neumann ,A. Marino \& K. Reichelt , Journal of crystal growth ,64(1983) 609-612.

[12] K. Duh \&H. preier , properties of PbSxSe1-x epilayers deposited onto PbS substrate by hot-wall epitaxy Journal Of Materials Science, 10(1975)1360- 1366 (Germany).

[13] N. Boukhris, H. Meradji, S. Ghemid, S. Drablia and F. El Haj Hassan,Ab initio study of the structural, electronic and thermodynamic properties of $\mathrm{PbSe}_{1-\mathrm{x}} \mathrm{S}_{\mathrm{x}}, \mathrm{PbSe}_{1-\mathrm{x}} \mathrm{Te}_{\mathrm{x}}$ and $\mathrm{PbS}_{1-\mathrm{x}} \mathrm{Te}_{\mathrm{x}}$ ternary alloys, Phys. Scr. 83 (2011) 065701.

[14] R.S.Popovic, Hall Effect Devices,2nd Edition,Bristol \&Philadelphia,(2000).

[15] S. Sree Harsha, "Principles Of Physical Vapor Deposition Of Thin Films" 1st edition, (2006).

[16] Teny Therea Jol,Meril Mathew, C.Sulha Karta, K.P.V.Joya Kumar, T.Abe \&Y.Iashiw aba,Vacuum, 80(2006)870- 875. 
[17] Ghusoon Jalil "Studying The Effect Of Preparation Parameters On The Structural And Electrical Properties Of ,Thesis ,M.SC,University Of Babylon,College Of Science (2002).

[18] Streetman \& SanJay Kumar Banerjee, Solid State Electronic Devices (2006).

[19] A. Rogalski \& K. Jozwikow ski, phy. Stat. sol, (a)111 (1989) 559 (Warsaw). 